\title{
Thyroid hormone transport by 4F2hc-IU12 heterodimers expressed in Xenopus oocytes
}

\author{
J W A Ritchie, G J Peter, Y-B Shi' ${ }^{1}$ and P M Taylor \\ Department of Anatomy and Physiology, University of Dundee, Dundee, DD1 4HN, Scotland UK \\ 'Laboratory of Molecular Embryology NICHD, National Institutes of Health, Bethesda MD 20892-543, USA \\ (Requests for offprints should be addressed to P M Taylor; Email: p.m.taylor@dundee.ac.uk.)
}

\begin{abstract}
Thyroid hormone $(\mathrm{TH})$ action and metabolism require hormone transport across cell membranes. We have investigated the possibility that $\mathrm{TH}$ are substrates of amino acid transport (System L) mediated by heterodimers of 4F2 heavy-chain (hc) and the light-chain (lc) permease IU12. Coexpression of 4F2hc and IU12 cDNAs injected into Xenopus oocytes induces saturable, $\mathrm{Na}^{+}$-independent transport of triiodothyronine $\left(\mathrm{T}_{3}\right)$, thyroxine $\left(\mathrm{T}_{4}\right)\left(\mathrm{K}_{\mathrm{m}}\right.$ of 1.8 and $6.3 \mu \mathrm{M}$ respectively), tryptophan and phenylalanine. Induced $\mathrm{TH}$ and
\end{abstract}

tryptophan uptakes are inhibited by excess $\mathrm{BCH}$ (synthetic System L substrate). Induced TH uptake is also inhibited by excess reverse tri-iodothyronine $\left(\mathrm{rT}_{3}\right)$, but not by triodothyroacetic acid (TRIAC) (TH analogue lacking an amino acid moiety). $\mathrm{T}_{3}$ and tryptophan exhibit reciprocal inhibition of their 4F2hc-IU12 induced uptake. Transport pathways produced by $4 \mathrm{~F} 2 \mathrm{hc}-\mathrm{lc}$ permease complexes may therefore be important routes for movement and exchange of TH (as well as amino acids) across vertebrate cell membranes, with a potential role in modulating TH action.

\section{Introduction}

The thyroid gland produces both thyroxine $\left(\mathrm{T}_{4}\right)$ and triiodothyronine $\left(\mathrm{T}_{3}\right)$ and releases them into the blood circulation, although much circulating $\mathrm{T}_{3}$ (the more active hormone) is generated by monodeiodination of $\mathrm{T}_{4}$ in liver and kidney (Oppenheimer et al. 1996, Hennemann \& Visser 1997). The major source of nuclear receptor-bound $T_{3}$ in many tissues (eg liver) is the blood $\mathrm{T}_{3}$ pool, although some tissues (eg brain) generate $\mathrm{T}_{3}$ endogenously from $\mathrm{T}_{4}$ (Oppenheimer et al. 1996, Hennemann \& Visser 1997). Movement of thyroid hormones between intra- and extra-cellular fluid compartments across the cell membrane is therefore an important step for modulation of hormone action and metabolism. Surprisingly, the specific mechanisms by which thyroid hormones cross the cell membrane are not fully understood, although movement by simple diffusion is likely to be a minor component of their total blood-tissue exchange (Hennemann et al. 1986, Blondeau et al. 1988, Chantoux et al. 1995, Blondeau et al. 1993, Zhou et al. 1992). Thyroid hormone (TH) transport into cells is inhibited by a wide variety of substances, including certain amino acids (notably tryptophan) (Blondeau et al. 1993, Zhou et al. 1990, Samson et al. 1992, Kemp \& Taylor 1997), bilirubin (Chantoux et al. 1993), bilirubin conjugates (Chantoux et al. 1993) and various structurally unrelated drugs (Chantoux et al. 1993, Abe et al. 1998). Recent reports (Abe et al. 1998, Friesema et al. 1999) show that thyroid hormones and sulfated derivatives are transported by organic anion transporters such as Ntcp and oatp1-3, but the molecular mechanism by which thyroid hormones and amino acids interact has not been elucidated.
There is evidence for a close functional link between transport of aromatic amino acids and thyroid hormones in erythrocytes (Zhou et al. 1992, Samson et al. 1992), hepatocytes (Blondeau et al. 1988, Kemp \& Taylor 1997) (by System T in both cases), placental choriocarcinoma cells (Prasad et al. 1994) and astrocytes (Blondeau et al. 1993) (by System L).

Recent studies have identified several members of a new family of amino acid permeases (eg LAT1, IU12/ASUR4 (Prasad et al. 1999, Mastroberardino et al. 1998, Torrents et al. 1998)) which exhibit activation of amino acid transport, having functional characteristics of System L, only when coexpressed with 4F2 heavy-chain (hc) glycoprotein. The highly-hydrophobic permeases light-chain (lc) interact covalently with $4 \mathrm{~F} 2 \mathrm{hc}$ to produce a functional, heteromeric 'transporter unit' in the cell membrane (Prasad et al. 1999, Mastroberardino et al. 1998, Torrents et al. 1998). The Xenopus lc permease IU12 (Torrents et al. 1998) is an early $\mathrm{T}_{3}$-response gene up-regulated during intestinal development (Liang et al. 1997) and it has been suggested that IU12 is involved in the signal transduction pathway of $\mathrm{T}_{3}$-induced metamorphosis (Liang et al. 1997). Here we demonstrate that the System L-like amino acid transport activity induced by coexpression of IU12 and 4F2hc in Xenopus oocytes accepts thyroid hormones as substrates, identifying an additional route for trans-membrane hormone transport which is also consistent with the proposed role of IU12 in transduction of $\mathrm{T}_{3}$ signals.

\section{Materials and Methods}

Xenopus laevis toads were purchased from the South African 


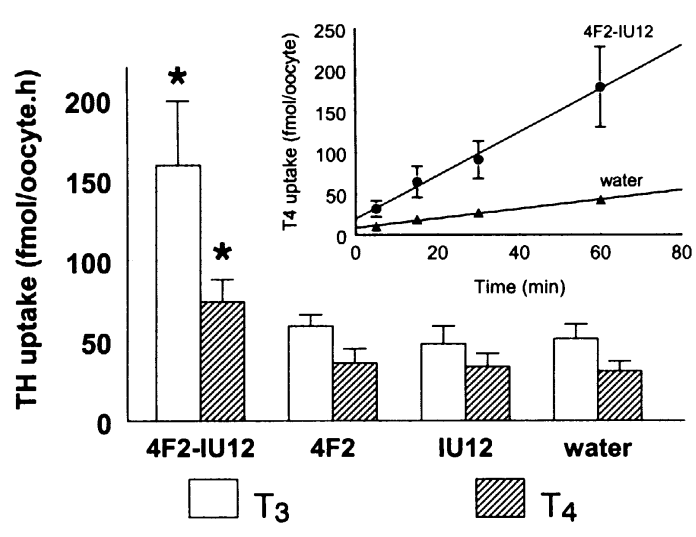

Figure 1 Uptake of thyroid hormones $\left(T_{3}, T_{4}\right.$ at $\left.0.1 \mu \mathrm{m}\right)$ by Xenopus oocytes 4 days after nuclear injection of $4 \mathrm{~F} 2 \mathrm{hc}$ and IU12 cDNA alone or in combination. Control oocytes were injected with water. Each bar represents mean uptake \pm S.E.M. measured in 5 separate batches of oocytes (using 8-11 individual oocytes per batch). ${ }^{*}$. Uptake value significantly different from corresponding value in water-injected oocytes with $P<0.01$. Inset:- time courses of $0.1 \mu \mathrm{M}\left[{ }^{125} \mid\right] \mathrm{T}_{4}$ uptake into oocytes injected with 4F2-IU12 DNAs or water (each point

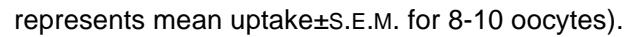

Xenopus Facility. Chemicals were obtained from Sigma (UK) with the exception of Collagenase A (Boehringer, UK) and Ultraspec water (Ambion, UK). Radiotracers were purchased from NEN (UK). cDNAs encoding IU12 (2.3 Kb EcoR1/Apa1 fragment from pBluescriptSK-IU12 (Liang et al. 1997)) and human 4F2hc (1.85 Kb EcoR1/BamH1 fragment from pSP654F2 (Teixeira et al. 1987)) were subcloned into the multiplecloning region of pSG5 (an SV-40 driven expression plasmid).

Oocytes were isolated by collagenase treatment (Peter et al. 1996) of ovarian tissue obtained from mature female Xenopus laevis toads. Defolliculated, stage V-VI (prophasearrested) oocytes were selected and maintained at $18{ }^{\circ} \mathrm{C}$ in Modified Barths Medium (MBM) containing (in $\mathrm{mM}$ ): 88 $\mathrm{NaCl}, 1 \mathrm{KCl}, 2.4 \mathrm{NaHCO}_{3}, 0.82 \mathrm{MgSO}_{4} .7 \mathrm{H}_{2} 0,0.66 \mathrm{NaNO}_{3}$, $0.75 \mathrm{CaCl}_{2} .2 \mathrm{H}_{2} \mathrm{O}$, 5.0 HEPES, pH 7.6 with Tris base, $10 \mathrm{mg} /$ liter gentamycin sulphate. For DNA injection, oocytes were transferred into individual wells of Tetraski plates pre-filled with $\mathrm{MBM}$ and centrifuged at $500 \mathrm{~g}$ for 10 minutes at $18{ }^{\circ} \mathrm{C}$, which causes migration of the nucleus to the cell surface and facilitates nuclear injection (Mertz \& Gurdon 1977). The visible nucleus of each oocyte was injected with 2 ng DNA in $15 \mathrm{nl}$ Ultraspec water using a pneumatic delivery system (Peter et al. 1996). For co-injection studies, 2 ng of both DNAs (ie 4F2hc/IUI2) were injected. Nuclei of control oocytes were injected with Ultraspec water. Oocytes were incubated in MBM at $18^{\circ} \mathrm{C}$ for 4 days to allow expression of injected DNA before experimentation.

Thyroid hormone transport in oocytes was measured as influx of $\left[{ }^{125} \mathrm{I}\right]$-labelled $\mathrm{T}_{3}$ and $\mathrm{T}_{4}$ tracers using a procedure (a)

(b)
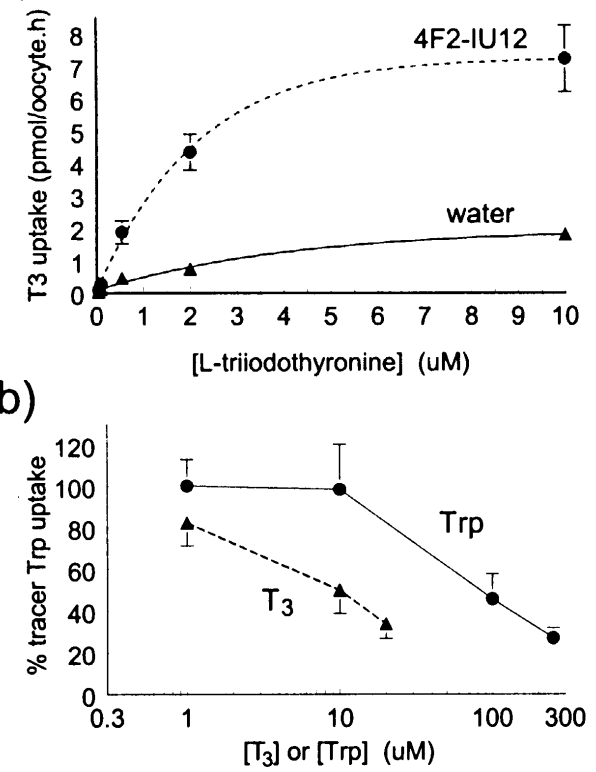

Figure 2 (a) Uptake of $T_{3}$ by oocytes injected with 4F2hc-IU12 DNAs or water as a function of external $\mathrm{T}_{3}$ concentration. Data are mean uptake \pm S.E.M. for 9-11 oocytes at each point, 4 days post-injection. Smallest error bars are masked by symbols. 4F2hc-IU12 induced $\mathrm{T}_{3}$ transport had an apparent $\mathrm{K}_{\mathrm{m}}$ of $1.8 \mu \mathrm{M}$ and $V_{\max }$ of $6.4 \pm 0.3 \mathrm{pmol} /$ oocyte.h. Tryptophan uptake in the same batch of oocytes had a $\mathrm{K}_{\mathrm{m}}$ of $70 \mu \mathrm{M}$ and $\mathrm{V}_{\max }$ of $180 \pm 54$ pmol/oocyte.h. (b) Concentration-dependent inhibition of 4F2hcIU12 induced $\left[{ }^{3} \mathrm{H}\right]$ tryptophan uptake by unlabelled $\mathrm{T}_{3}$ or tryptophan. Data show uptake of tryptophan $(1 \mu \mathrm{M}$ tracer) in presence of increasing concentrations of unlabelled inhibitor, as a percentage of control uptake in absence of inhibitor. Each point represents mean value \pm S.E.M. for 8-11 4F2hc-IU12-injected oocytes, after appropriate correction for uptake in water-injected oocytes.

described previously for amino acid uptake (Peter et al. 1996). All experiments were carried out at $22{ }^{\circ} \mathrm{C}$ using $\mathrm{Na}^{+}$-free transport buffer (unless otherwise stated) containing $100 \mathrm{mM}$ tetramethylammonium chloride (TMACl), $2 \mathrm{mM} \mathrm{KCl} ; 1 \mathrm{mM}$ $\mathrm{CaCl}_{2} ; 1 \mathrm{mM} \mathrm{MgCl}$; $10 \mathrm{mM}$ HEPES, pH 7.5 with Tris). Radiolabelled amino acid uptake $\left(\left[{ }^{3} \mathrm{H}\right]\right.$-phenylalanine or $\left[{ }^{3} \mathrm{H}\right]$ tryptophan over $30 \mathrm{~min}$ ) was also measured (Peter et al. 1996). BCH (5 mM) was used as a specific inhibitor of amino acid transport System L.

Data are expressed as mean values \pm standard error of the mean (S.E.M.; $n=$ number of observations). Experimental measurements in each batch of oocytes were made on $7-11$ individual oocytes. Differences between mean values were assessed using Students unpaired t-test, with significance assigned at $P<0.05$. 


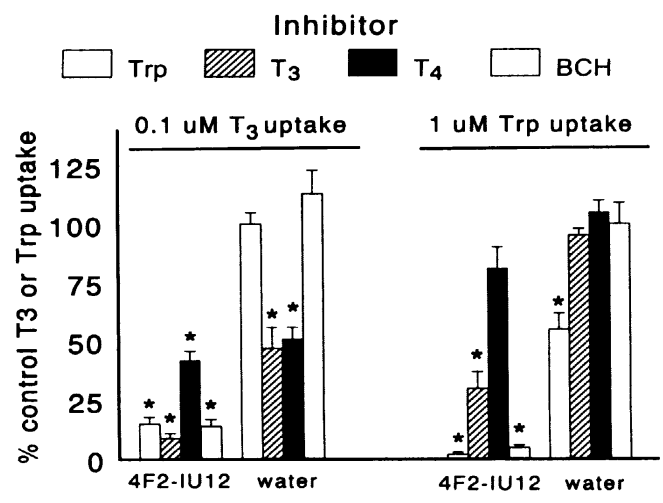

Figure 3 Inhibition of $\mathrm{T}_{3}(0.1 \mu \mathrm{M})$ and tryptophan $(1 \mu \mathrm{M})$ uptake by iodothyronines, tryptophan and 2-endoamino-bicycloheptane2-carboxylic acid $(\mathrm{BCH})$ in Xenopus oocytes injected with 4F2hc-IU12 cDNAs or water. Inhibitor concentrations were $10 \mu \mathrm{M}$ for $\mathrm{T}_{3}$ and $\mathrm{T}_{4}, 5 \mathrm{mM}$ for $\mathrm{BCH}$ and $10 \mathrm{mM}$ for trytophan. Each bar represents uptake in the presence of inhibitor as a percentage of control uptake measured in absence of inhibitor (mean value \pm S.E.M. for 7-11 oocytes). Control $\mathrm{T}_{3}$ uptakes were $71 \pm 7$ and $22 \pm 3 \mathrm{fmol} /$ oocyte.h for 4F2hc-IU12- and waterinjected oocytes respectively. Control tryptophan uptakes were $10.2 \pm 0.4$ and $2.1 \pm 0.1 \mathrm{pmol} / \mathrm{oocyte}$.h for 4F2hc-IU12- and water-injected oocytes respectively. Similar results were obtained using a different batch of oocytes. * Significant reduction of uptake in presence of inhibitor $(P<0.005)$.

\section{Results}

Functional expression of 4F2hc-IU12 heterodimers in oocytes after nuclear injection of cDNAs was established in preliminary experiments (data not shown) as a marked, 2endoamino-bicycloheptane-2-carboxylic acid (BCH)inhibitable induction of uptake of $\left[{ }^{3} \mathrm{H}\right]$ phenylalanine and $\left[{ }^{3} \mathrm{H}\right]$ tryptophan (averaging $120 \mathrm{pmol} /$ oocyte.h for both amino acids at $50 \mu \mathrm{M})$ relative to uptake in water-injected cells (10 pmol/oocyte.h). Induced phenylalanine uptake was stable between 2-4 days post-injection. Uptake of both T3 and T4 $(0.1 \mu \mathrm{M})$ was also significantly increased in 4F2hc-IU12 injected oocytes compared to oocytes injected with a single DNA or water (Fig. 1). The time course of [ $\left.{ }^{125} \mathrm{I}\right]$-labelled $\mathrm{T}_{3}$ and $\mathrm{T}_{4}$ uptake into oocytes was linear for least 2 hours (eg Fig. 1); all TH studies reported below involved a 60 min uptake period using oocytes at 4 days post-injection. The average increase in uptake over control (water- or IU12-injected oocytes) was $2.1 \pm 0.5$ and $2.7 \pm 0.35$ times for $\mathrm{T}_{4}$ and $\mathrm{T}_{3}$ respectively ( $n=5$ batches of oocytes). Induced TH uptakes were saturable and showed mutual cross-inhibition (Figs 2a, 3; data shown for $\mathrm{T}_{3}$ only). Induced $\mathrm{T}_{3}$ and $\mathrm{T}_{4}$ uptakes measured over a concentration range of $0.05-10 \mu \mathrm{M}$ (the latter close to the limit of iodothyronine solubility) had for $\mathrm{T}_{3}$, an apparent $\mathrm{K}_{\mathrm{m}}$ value of $1.8 \mu \mathrm{M}$ and $\mathrm{V}_{\max }$ of $6.4 \pm 0.3 \mathrm{pmol} /$ oocyte.h (Fig. 2a) and for $\mathrm{T}_{4}$, a $\mathrm{K}_{\mathrm{m}}$ of $6.3 \mu \mathrm{M}$ and $\mathrm{V}_{\max }$ of $2.0 \pm 0.6 \mathrm{pmol} /$ oocyte.h. Induced $0.1 \mu \mathrm{M}$ TH uptake differed markedly from basal TH uptake measured in control (water-injected) oocytes in that it was significantly inhibited by excess $\mathrm{BCH}$ and tryptophan (Fig. 3, data shown for $\mathrm{T}_{3}$ only). The 4F2hc-IU12 induced uptake of $\left[{ }^{3} \mathrm{H}\right]$-tryptophan is also inhibited by $\mathrm{BCH}$ (Fig. 3) and shows concentration-dependent inhibition by unlabelled $\mathrm{T}_{3}$ and tryptophan (Fig. 2b), although inhibition by $\mathrm{T}_{4}(10 \mu \mathrm{M})$ has not achieved statistical significance (Fig. 3). The natural iodothyronine reverse tri-iodothyronine $\left(\mathrm{rT}_{3}\right)(10$ $\mu \mathrm{M})$ inhibited induced $0.1 \mu \mathrm{M} \mathrm{T} \mathrm{T}_{3}$ uptake by $41 \pm 4 \%(n=3$ preparations), but the synthetic iodothyronine analogue triodothyroacetic acid (TRIAC) did not inhibit $\mathrm{T}_{3}$ (or tryptophan) uptake in either 4F2hc-IU12- or water-injected oocytes (data not shown).

Substitution of $\mathrm{TMA}^{+}$with $100 \mathrm{mM} \mathrm{Na}{ }^{+}$did not have a significant effect on $\mathrm{TH}$ or tryptophan uptake, nor did preincubation of oocytes with $1 \mathrm{nM} \mathrm{T}_{3}$ and $\mathrm{T}_{4}$ for $48 \mathrm{~h}$ prior to transport measurement at 4-days post-injection.

\section{Discussion}

In the present study, we provide evidence which indicates that amino acid transport activity produced by 4F2hc-IU12 heterodimers accepts thyroid hormones $\left(\mathrm{T}_{4}\right.$ and $\left.\mathrm{T}_{3}\right)$ as substrates. The 4F2hc-IUI2 induced uptakes of $\mathrm{T}_{3}$ and tryptophan in oocytes show mutual inhibition and are both $\mathrm{Na}^{+}$-independent and inhibited by excess $\mathrm{BCH}$, confirming that the expressed transport activity is System L. To our knowledge, this is the first report of thyroid hormone transport by a cloned amino acid transporter. Other recent studies (Abe et al. 1998, Friesama et al. 1999) demonstrate that organic anion transporters also accept $\mathrm{TH}$ and other iodothyronines as substrates, providing both $\mathrm{Na}^{+}$-dependent (Ntcp (Friesema et al. 1999)) and $\mathrm{Na}^{+}$-independent (oatp 1-3 (Abe et al. 1998, Friesama et al. 1999)) transport pathways. The present results indicate that amino acid transporters producing System L-like activity may provide an important route for physiologically-relevant movements of TH across cell membranes. Furthermore, in combination with the knowledge that $\mathrm{TH}$ are also substrates for organic anion transporters, the results provide a rational basis for explaining the wide variety of reported inhibitors of cellular TH transport (Zhou et al. 1990, Samson et al. 1992, Kemp \& Taylor 1997, Chantoux et al. 1993, Abe et al. 1998.).

4F2hc-IU12-induced $\mathrm{TH}$ transport is inhibited by $\mathrm{rT}_{3}$, indicating that System $\mathrm{L}$ may transport a variety of iodothyronines. $\mathrm{T}_{4}, \mathrm{~T}_{3}$ and $\mathrm{rT}_{3}$ are large, iodinated tyrosine derivatives retaining an amino acid functional motif which presumably enables recognition by the System L binding site; this view is supported by the observation that TRIAC (a $\mathrm{T}_{3}$ analogue lacking the amino acid moiety) does not inhibit induced TH or tryptophan uptake. 4F2hc-IU12 induced TH transport appears to be of high affinity relative to tryptophan transport but, in contrast, there is a marked sequential reduction in apparent $\mathrm{V}_{\max }$ for induced transport of tryptophan, 
$\mathrm{T}_{3}$ and $\mathrm{T}_{4}(180,6.4$ and $2 \mathrm{pmol} /$ oocyte.h respectively in the same oocyte batch). This reduction in transport capacity correlates with increasing size of the substrate molecule and may therefore reflect increasing steric hinderence of the transport mechanism, especially by the large iodides of $T_{3}$ and $\mathrm{T}_{4}$. Bulky phenylglucosides show analogous reductions in apparent $\mathrm{V}_{\max }$, for the glucose transporter SGLT1 (Lostao et al. 1994), due to impeded translocation across the cell membrane.

System L transport and $4 \mathrm{~F} 2 \mathrm{hc}$ protein are ubiquitously expressed in mammalian tissues ((Palacin et al. 1998, Taylor $e t$ al. 1999) for review), although the lc permeases identified thus far have distinct, relatively restricted tissue distributions (Prasad et al. 1999, Mastroberardino et al. 1998, Torrents et al. 1998, Liang et al. 1997, Gaugitsch et al. 1992). We have not examined $\mathrm{TH}$ transport properties of lc permeases other than IU12 but, given the broad substrate scope of amino acid transport related to expression of $4 \mathrm{~F} 2 \mathrm{hc}$ (and its analogue NBAT) (Palacin et al. 1998), we might predict that TH are carried by mammalian homologues of IU12 such as LAT1 (which also expresses System L-like activity) (Prasad et al. 1999, Mastroberardino et al. 1998), providing important routes for TH transport and exchange in many tissues. A countertransport mechanism for cellular $\mathrm{TH}$ accumulation driven by hetero-exchange of $\mathrm{T} 3$ with intracellular aromatic amino acids has been proposed (Zhou et al. 1992, Zhou et al. 1990), which is consistent with the known mechanism of $4 \mathrm{~F} 2 \mathrm{hc}-1 \mathrm{c}$ induced amino acid transport (Prasad et al. 1999, Mastroberardino et al. 1998, Torrents et al. 1998). This type of exchange might include physiologically-relevant $\mathrm{T}_{4} / \mathrm{T}_{3}$ exchanges across cell membranes in tissues such as liver and kidney (Hennemann \& Visser 1997, Zhou et al. 1992, Taylor et al. 1998). The $K_{m}$ for $\mathrm{T}_{3}$ uptake reported here for 'cloned' System $\mathrm{L}(1.8 \mu \mathrm{M})$ is of similar order to those reported for TH uptake by cloned organic anion transporters (Abe et al. 1998, Friesema et al. 1999), and also has a value similar to the $\mathrm{K}_{\mathrm{m}}$ for $\mathrm{T}_{3}$ uptake (reportedly by System $\mathrm{L}_{1}$ ) in cultured astrocytes (Blondeau et al. 1993). However this value is at least an order of magnitude higher than those reported in other cell types (eg hepatocytes, erythrocytes) where $\mathrm{TH}$ are transported by a mechanism termed System T (Blondeau et al. 1988, Chantoux et al. 1995, Zhou et al. 1992, Zhou et al. 1990, Kemp \& Taylor 1997). It is possible that System T transport is mediated by a novel, as yet unidentified, lc permease with higher affinity fo TH. An alternative possibility is that $\mathrm{TH}$ transport in certain tissues is facilitated by binding of hormone to surface receptors as a prerequisite to transport across the cell membrane (Zhou et al. 1990, Kemp \& Taylor 1997, Samson et al. 1996, Gharbi-Chihi \& Torresani 1981). We (Kemp \& Taylor 1997, Taylor et al. 1998) and others (Samson et al. 1992, Gharbi-Chihi \& Torresani 1981) have hypothesized that interactions between receptor and transporter proteins enable thyroid hormones to be 'channelled' to amino acid transport mechanisms in the cell membrane under certain circumstances. It is conceivable that $\mathrm{TH}$ receptor proteins are brought into functional contact with lc permeases by mutual interactions within a $4 \mathrm{~F} 2 \mathrm{hc}-$ related protein complex. 4F2hc-IU12, Ntcp and oatp transporters expressed in oocytes all accept both $\mathrm{T}_{3}$ and $\mathrm{T}_{4}$ as substrates, therefore responsibility for apparent differences between the transport mechanism for the two hormones in certain mammalian cell types (eg Hennemann et al. 1986, Chantoux et al. 1995, Kemp \& Taylor 1997)) must reside elsewhere, possibly at the level of surface TH receptors (Kemp \& Taylor 1997, Taylor et al. 1998).

Regulation of $\mathrm{TH}$ action and inter-organ $\mathrm{TH}$ metabolism involves combined action of transporters for free $\mathrm{TH}$ and conjugates (notably TH sulfates) at the cell membrane in series with intracellular deiodinases and sulfotransferases/sulfatases (Oppenheimer et al. 1996 Hennemann et al. 1997, Taylor et al. 1999). The $K_{m}$ values for $T_{3}$ transport by $4 F 2 h c-I U 12$ and organic anion transporters are markedly higher than plasma free TH concentrations, but this would ensure a linear change of uptake with free hormone concentration as required of a component in TH signalling (Oppenheimer et al. 1996, Hennemann et al. 1997, Taylor et al. 1999). On the other hand, the $\mathrm{T}_{3} \mathrm{~K}_{\mathrm{m}}$ value for $4 \mathrm{~F} 2 \mathrm{hc}-\mathrm{IU} 12$ is lower than those reported for non-iodinated amino acid substrates (eg Trp, Leu, Phe, Gln, His) of 4F2hc-lc permease heterodimers $\left(\mathrm{K}_{\mathrm{m}}>20 \mu \mathrm{M}\right.$ (Prasad et al. 1999, Mastroberardino et al. 1998, Torrents et al. 1998)), which should help $\mathrm{T}_{3}$ compete effectively for transport under physiological conditions. Thyroid hormones play an important role in vertebrate development (Oppenheiner et al. 1996, Hennemann et al. 1997, Liang et al. 1997, Shi et al. 1996). IU12 is a TH-regulated gene, at least during amphibian development (Liang et al. 1997), providing a possible mechanism by which the hormone regulates its own action and metabolism by modulating cellular entry. Tissue-specific, temporal regulation of expression of IU12 (Liang et al. 1997) (or other lc permeases) may also help determine cellular competence to respond to extracellular TH signals; this may have particular importance during development (Shi et al. 1996). Expression of mammalian homologues of IU12 is associated with cell activation and carcinogenesis as well as tissue development (Prasad et al. 1999, Gaugitsch et al. 1992, Sang et al. 1995). Our results indicate that the functions of these proteins may include modulation of TH signalling as well as amino acid supply for protein synthesis and other processes of cell metabolism.

\section{Ackowledgements}

This work was supported by the UK BBSRC, The Wellcome Trust and University of Dundee. We thank Professor R Hume for useful comments on the manuscript, Dr L C Kühn for a gift of 4F2hc DNA and Mrs T B Panova for technical assistance.

\section{References}

Abe T, Kakyo M, Kagami H, Tokui T, Nishio T, Tanemoto M, Nomura H, Hebert SC, Matsuno S, Kondo H \& Yawo H 1998 Molecular characterization and tissue distribution of a new organic anion transporter subtype (oatp3) that transports thyroid hormones and 
taurocholate and comparison with oatp2. Journal of Biological Chemistry 273 22395-22401.

Blondeau JP, Beslin A, Chantoux F \& Francon J 1993 Triiodothyronine is a high-affinity inhibitor of amino acid transport system L1 in cultured astrocytes. Journal of Neurochemistry $\mathbf{6 0}$ 1407-1413.

Blondeau JP, Osty J \& Francon J 1988 Characteristics of the thyroid hormone transport system of isolated hepatocytes. Journal of Biological Chemistry 263 2685-2692.

Chantoux F, Blondeau JP \& Francon J 1995 Characterization of the thyroid hormone transport system of cerebrocortical rat neurons in primary culture. Journal of Neurochemistry 65 2549-2554.

Chantoux F, Chuniaud L, Dessante M, Trivin F, Blondeau JP \& Francon J 1993 Competitive inhibition of thyroid hormone uptake into cultured rat brain astrocytes by bilirubin and bilirubin conjugates. Molecular and Cellular Endocrinology 97 145-151.

Friesema ECH, Docter R, Moerings EPCM, Stieger B, Hagenbuch B, Meier PJ, Krenning EP, Hennemann G \& Visser TJ 1999 Identification of thyroid hormone transporters. Biochemical and Biophysical Research Communications 254 497-501.

Gaugitsch HW, Prieschl EE, Kalthoff F, Huber NE \& Baumruker TA 1992 A novel transiently expressed, integral membrane protein linked to cell activation. Molecular cloning via the rapid degradation signal AUUUA. Journal of Biological Chemistry 267 11267-11273.

Gharbi-Chihi J \& Torresani J 1981 Thyroid hormone binding to plasma membrane preparations: studies in different thyroid states and tissues. Journal of Endocrinological Investigation 4 177-183.

Hennemann G, Krenning EP, Polhuys M, Mol JA, Bernard BF, Visser TJ \& Docter R 1986 Carrier-mediated transport of thyroid hormone into rat hepatocytes is rate-limiting in total cellular uptake and metabolism. Endocrinology 119 1870-1872.

Hennemann G \& Visser TJ 1997 Thyroid hormone synthesis, plasma membrane transport and metabolism. Pharmacotherapeutics of the thyroid gland. In Handbook of Experimental Pharmacology, vol 128, pp 75-117. Eds AP Weetman \& A Grossman. Berlin/New York: Springer-Verlag.

Kemp HF \& Taylor PM 1997 Interactions between thyroid hormone and tryptophan transport in rat are modulated by thyroid status. American Journal of Physiology 272 E809-E816.

Liang V-C, Sedgwick T \& Shi Y-B 1997 Characterization of the Xenopus homolog of an immediate early gene associated with cell activation: sequence analysis and regulation of its expression by thyroid hormone during amphibian metamorphosis. Cell Research 7 179-193.

Lostao MP, Hirayama BA, Loo DDF \& Wright EM 1994 Phenylglucosides and the Na+/glucose cotransporter (SGLT1): analysis of interactions. Journal of Membrane Biology 142 161-170.

Mastroberardino L, Spindler B, Pfeiffer R, Skelly PJ, Loffing J, Shoemaker CB \& Verrey F 1998 Amino-acid transport by heterodimers of $4 \mathrm{~F} 2 \mathrm{hc} / \mathrm{CD} 98$ and members of a permease family. Nature 395 288-291.

Mertz JE \& Gurdon JB 1977 Purified DNAs are transcribed after microinjection into Xenopus oocytes. Proceedings of the National Academy of Sciences of the USA 74 1502-1506.

Oppenheimer JH, Schwartz HL \& Strait KA 1996 Peripheral Hormone Metabolism. In The Thyroid, pp 162-184. Eds LE Braverman \& R Utiger. Philadelphia: Lippincott-Raven.
Palacin M, Estevez R, Bertran J \& Zorzano A 1998 Molecular biology of mammalian plasma membrane amino acid transporters. Physiological Reviews 78 969-1054.

Peter GJ, Davidson IG, Ahmed A, MCllroy L, Forrester AR \& Taylor PM 1996 Multiple components of arginine and phenylalanine transport induced in neutral and basic amino acid transporter cRNA injected Xenopus oocytes. Biochemical Journal 318 915-922.

Prasad PD, Leibach FH, Mahesh VB \& Ganapathy V 1994 Relationship between thyroid hormone transport and neutral amino acid transport in JAR human choriocarcinoma cells. Endocrinology 134 574-581.

Prasad PD, Wang H, Huang W, Kekuda R, Rajan DP, Leibach FH \& Ganapathy V 1999 Human LAT1, a subunit of system L amino acid transporter: Molecular cloning and function. Biochemical and Biophysical Research Communications 255 283-288.

Samson M, Osty J, Francon J \& Blondeau JP 1992 Triiodothyronine binding sites in the rat erythrocyte membrane: involvement in triiodothyronine transport and relation to the tryptophan transport System T. Biochimica et Biophysica Acta 1108 91-98.

Samson M, Osty J, Thibout H \& Blondeau JP 1996 Solubilization, reconstitution and molecular properties of the triiodothyronine transport protein from rat erythrocyte membranes. European Journal of Endocrinology 134 660-668.

Sang J, Lim YP, Panziaca M, Finch P \& Thompson NL 1995 A1, a highly conserved oncofetal complementary DNA from rat hepatoma, encodes an integral membrane protein associated with liver development, carcinogenesis, and cell activation. Cancer Research 55 1152-1159.

Shi Y-B, Wong J, Puzianowska-Kuznicka M \& Stolow MA 1996 Tadpole competence and tissue-specific temporal regulation of amphibian metamorphosis: roles of thyroid hormone and its receptors. Bioessays 18 391-399.

Taylor PM, Kemp HF, Davies A, Birrell J \& Peter GJ 1998 Aromatic amino acid transport in liver and kidney and possible links with transport of thyroid hormones. Nova Acta Leopoldina $306223-$ 233.

Taylor PM, Rennie MJ \& Low SY 1999 Biomembrane transport and inter-organ nutrient flows: the amino acids. In Biomembrane Transport, pp 295-325. Ed L Van Winkle. New York: Academic Press.

Teixeira S, Di Grandi S \& Kühn LC 1987 Primary structure of the human $4 \mathrm{~F} 2$ antigen heavy chain predicts a transmembrane protein with a cytoplasmic NH2 terminus. Journal of Biological Chemistry 262 9574-9580.

Torrents D, Estevez R, Pineda M, Fernandez E, Lioberas J, Shi Y-B, Zorzano A \& Palacin M 1998 Identification and characterization of a membrane protein $\left(\mathrm{y}^{+} \mathrm{L}\right.$ amino acid transporter- 1$)$ that associates with $4 \mathrm{~F} 2 \mathrm{hc}$ to encode the amino acid transport activity $\mathrm{y}^{+}$L. Journal of Biological Chemistry 273 32437-32445.

Zhou Y, Samson M, Francon J \& Blondeau JP 1992 Thyroid hormone concentrative uptake in rat erythrocytes. Biochemical Journal 281 81-86.

Zhou Y, Samson M, Francon J \& Blondeau JP 1990 Evidence for a close link between the thyroid hormone transport system and the aromatic amino acid transport system $\mathrm{T}$ in erythrocytes. Journal of Biological Chemistry 265 17000-17004. 